\title{
The Protective Role of Manganese Superoxide Dismutase Against Adriamycin-induced Acute Cardiac Toxicity in Transgenic Mice
}

\author{
Hsiu-Chuan Yen, ${ }^{\star}$ Terry D. Oberley, ${ }^{\ddagger}$ Satit Vichitbandha, ${ }^{\star}$ Ye-Shih Ho, ${ }^{\S}$ and Daret K. St. Clair ${ }^{\star}$ \\ *University of Kentucky, Graduate Center for Toxicology, Lexington, Kentucky 40536; ${ }^{\ddagger}$ University of Wisconsin, Department of \\ Pathology and VA Hospital, Madison, Wisconsin 53705; and ${ }^{\S}$ Wayne State University, Institute of Chemical Toxicology, Detroit, Michigan \\ 48201
}

\begin{abstract}
Adriamycin (ADR) is a potent anticancer drug known to cause severe cardiac toxicity. Although ADR generates free radicals, the role of free radicals in the development of cardiac toxicity and the intracellular target for ADR-induced cardiac toxicity are still not well understood. We produced three transgenic mice lines expressing increased levels of human manganese superoxide dismutase (MnSOD), a mitochondrial enzyme, as an animal model to investigate the role of ADR-mediated free radical generation in mitochondria. The human MnSOD was expressed, functionally active, and properly transported into mitochondria in the heart of transgenic mice. The levels of copper-zinc SOD, catalase, and glutathione peroxidase did not change in the transgenic mice. Electron microscopy revealed dose-dependent ultrastructural alterations with marked mitochondrial damage in nontransgenic mice treated with ADR, but not in the transgenic littermates. Biochemical analysis indicated that the levels of serum creatine kinase and lactate dehydrogenase in ADR-treated mice were significantly greater in nontransgenic than their transgenic littermates expressing a high level of human MnSOD after ADR treatment. These results support a major role for free radical generation in ADR toxicity as well as suggesting mitochondria as the critical site of cardiac injury. (J. Clin. Invest. 1996. 98:12531260.) Key words: free radicals • mitochondria • antioxidants $\bullet$ heart $\bullet$ antineoplastic agents
\end{abstract}

\section{Introduction}

Adriamycin $(\mathrm{ADR})^{1}$, a quinone-containing anthracycline antibiotic, is an important anticancer drug used in treating a wide

Part of this work has been presented as an abstract less than 400 words at the annual meeting of the Oxygen Society, the Ritz-Carlton Huntington Hotel, Pasadena, CA., Abstract 1-101, November 16-20, 1995.

Address correspondence to Daret K. St. Clair, Ph.D., Graduate Center for Toxicology, University of Kentucky, 342 Health Sciences Research Building, Lexington, KY 40536. Phone: 606-257-3956; 606323-1059.

Received for publication 4 January 1996 and accepted in revised form 19 June 1996.

1. Abbreviations used in this paper: ADR, adriamycin; CAT, catalase; CK, creatine kinase; GPX, glutathione peroxidase; LDH, lactate dehydrogenase.

J. Clin. Invest.

(C) The American Society for Clinical Investigation, Inc.

0021-9738/96/09/1253/08 \$2.00

Volume 98, Number 5, September 1996, 1253-1260 spectrum of human neoplasms, but the development of severe cardiac toxicity in humans compromises its clinical effectiveness (for review see reference 1). The cardiac toxicity has been well established using both physiological and ultrastructural studies (1), and has been shown after both chronic and acute treatment $(1,2)$. It has been demonstrated that ADR is metabolically activated to a free radical state and interacts with molecular oxygen to generate superoxide radicals (for review see references 3 and 4). It has been postulated that superoxide is generated through redox cycling of ADR in vivo. Superoxide radicals can react with hydrogen peroxide to form highly reactive hydroxyl radicals via the iron catalyzed Haber-Weiss reaction. The secondarily derived hydroxyl radicals can cause protein and DNA damage and initiate lipid peroxidation (5). Increased lipid peroxidation, and enhanced free radical generation in the heart have been demonstrated after administration of ADR (1-4, 6-8). However, whether free radicals generated by ADR are responsible for the cardiac toxicity is not certain because of difficulties in interpreting results obtained from studies using exogenous antioxidants (4). First, the results from different studies have not been consistent partially because of the biochemical methods used $(3,4)$. Second, the entry of exogenous antioxidants into cells has not been demonstrated in these studies. Finally, the intracellular localization of these antioxidants was not identified.

Superoxide dismutase (SOD), catalase (CAT), and glutathione peroxidase (GPX) are the primary antioxidant enzymes in mammalian tissues. SOD catalyzes the dismutation of superoxide to hydrogen peroxide, which is further detoxified by CAT and GPX (9). In humans, there are three forms of SOD: a homodimeric CuZnSOD found primarily in the cytosol (10), a homotetrameric glycosylated CuZnSOD in the extracellular space (11), and a homotetrameric MnSOD in the mitochondrial matrix (12). Mitochondria are the primary source of endogenous superoxide radicals under normal physiological conditions (13), and are susceptible to oxidative damage, especially in myocardial tissue $(14,15)$. Although mitochondrial dysfunction, as documented by inhibition of oxidative phosphorylation, decreased ATP synthesis, and disrupted calcium homeostasis with subsequent cell death, has been observed in ADR-induced cardiac toxicity (1, 8, 16-19), additional subcellular alterations including intracytoplasmic vacuoles, dilated sarcoplasmic reticulum, and myofibril disarray have also been identified (1). Therefore, it is not clear whether mitochondria are indeed the primary target for ADRinduced cardiac toxicity, or whether the mitochondrial injury is a secondary event after the damage of other organelles.

To investigate the significance of free radical generation and determine whether mitochondria are the primary target in ADR-induced cardiac toxicity, we produced transgenic mice which expressed increased levels of human MnSOD under the control of the human $\beta$-actin promoter. The expression, local- 
ization, and levels of human MnSOD were extensively characterized. The extent of ADR-induced cardiac toxicity was determined by ultrastructural pathology studies of the heart tissues in mice. The total serum creatine kinase (CK) and lactate dehydrogenase ( $\mathrm{LDH}$ ) activities were also monitored in mice after ADR treatment.

\section{Methods}

Construct of the transgene. The construct of the human MnSOD transgene is shown in Fig. 1. The transgene consists of human MnSOD cDNA and the human $\beta$-actin 5' flanking sequence and promoter. It was constructed by inserting the human MnSOD cDNA (20) flanked by EcoRI restriction sites into the human $\beta$-actin expression vector pHßAPr-1 (21) as described previously (22). The fragment of the construct without the plasmid was further purified for producing transgenic mice.

Generation and maintenance of transgenic mice. The transgene was introduced into the pronuclei of mouse fertilized eggs by microinjection as described by Hogan et al. (23). This procedure was performed in the Transgenic Facility at the University of Kentucky. The mice used for producing transgenic mice were the $\mathrm{F} 1$ progeny of C57BL/6 $\times \mathrm{C} 3 \mathrm{H}$ hybrids $(\mathrm{B} 6 \mathrm{C} 3)$ which were purchased from Harlan Sprague Dawley (Indianapolis, IN). Four founders with stably integrated human MnSOD transgenes were identified by Southern analysis from mouse tail DNA. Three transgenic mice lines were produced and maintained from three founders. All transgenic mice were propagated as heterozygous transgenic mice. The mice used in the present study were from the inbred of $\mathrm{B} 6 \mathrm{C} 3$ mice.

Southern blot analysis. To identify transgenic mice carrying the human MnSOD transgene, genomic DNA was isolated from mouse tail as described by Laird et al. (24). Tail DNA was digested with the restriction enzyme PstI, separated on a $0.9 \%$ agarose gel and transferred to Nytran paper (Schleicher \& Schuell, Keene, NH). The blot was air dried, baked, prehybridized, hybridized with the ${ }^{32} \mathrm{P}$-labeled human MnSOD cDNA probe, and subsequently washed under high stringency conditions as described previously (25). The blot was then exposed to Kodak XAR film at $-80^{\circ} \mathrm{C}$.

Northern analysis. Total RNA from the heart tissues of nontransgenic mice and transgenic mice was isolated by the guanidine isothiocyanate method as described (26). Total RNA (20 $\mu \mathrm{g} / \mathrm{lane})$ was sizeseparated by formaldehyde-agarose $(1.1 \%)$ gel electrophoresis and transferred to Nytran paper (Schleicher \& Schuell). Hybridization, washing, and autoradiography were performed as described for Southern analysis.

SOD activity gel. SOD activity gel was performed according to the method described by Beauchamp and Fridovich (27) with slight modifications. Tissues were homogenized in $50 \mathrm{mM}$ potassium phosphate buffer ( $\mathrm{pH}$ 7.8). $200 \mu \mathrm{g}$ protein/lane was electrophoresed through a nondissociating riboflavin gel consisting of $5 \%$ stacking gel (pH 6.8) and a $10 \%$ running gel $(\mathrm{pH} 8.8)$ at $4^{\circ} \mathrm{C}$. To visualize SOD activity, gels were first incubated in $2.43 \mathrm{mM}$ nitro blue tetrazolium (NBT) in deionized water for $15 \mathrm{~min}$ and then in $0.028 \mathrm{mM}$ riboflavin/ $280 \mathrm{mM} \mathrm{N}, \mathrm{N}, \mathrm{N}^{\prime}, \mathrm{N}^{\prime}$ - tetramethyl-ethylenediamine (TEMED) in 50 $\mathrm{mM}$ potassium phosphate buffer ( $\mathrm{pH} 7.8$ ) for $15 \mathrm{~min}$ in the dark. Gels

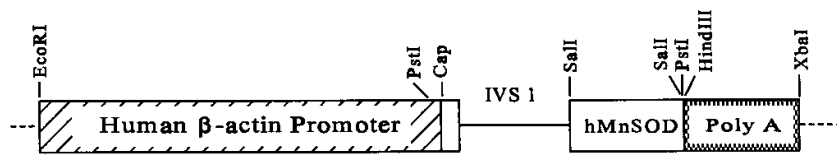

$1 \mathrm{~Kb}$

Figure 1. Construct of the human MnSOD transgene. IVS1, intervening sequence 1 from the human $\beta$-actin gene; hMnSOD, human MnSOD cDNA; Kb, kilobase. were then washed in deionized water and illuminated under fluorescent light until clear zones of SOD activity were distinctly evident.

SOD activity assay. The heart homogenate was used for SOD activity assay. SOD activities were measured by the NBT-bathocuproine sulfonate (BCS) reduction inhibition method as described by Spitz and Oberley (28). $5 \mathrm{mM}$ sodium cyanide was used to inhibit $\mathrm{CuZnSOD}$ and thus measure only MnSOD activity. BCS and sodium cyanide were purchased from Aldrich Chemical Company (Milwaukee, WI).

$C A T$ and GPX activity assay. Heart homogenates were centrifuged at $8,000 \mathrm{~g}$ and the supernatant was used to measure GPX and CAT activities. CAT activity was measured as described by Beers and Sizer (29). GPX activity was measured as described (30,31). $0.25 \mathrm{mM}$ hydrogen peroxide was used as the substrate for the GPX assay.

Immunogold staining for human MnSOD. Tissues were cut in 1- $\mathrm{mm}^{3}$ blocks and fixed in Carson Millonig's fixative (4\% formaldehyde in $0.16 \mathrm{M}$ monobasic sodium phosphate buffer, $\mathrm{pH}$ 7.2) for electron immunogold analysis and processed as previously described (32).

Animal treatment. 11 to 13 -wk-old-mice were treated with ADR ( $2 \mathrm{mg} / \mathrm{ml}$ in saline, purchased from Adria Laboratories, Columbus, $\mathrm{OH})$ intraperitoneally at total doses of 10,20 , or $25 \mathrm{mg} / \mathrm{kg}$. Animals were killed after $5 \mathrm{~d}$ and the hearts were removed and further processed for pathological studies. For the study of serum CK and LDH activities, male mice were treated with $25 \mathrm{mg} / \mathrm{kg}$ of ADR for $3 \mathrm{~d}$ and blood was collected by cardiac puncture. Animals were anesthetized with $65 \mathrm{mg} / \mathrm{kg}$ of phentobarbital (The Butler Company, Columbus, $\mathrm{OH})$ before being killed.

Electron microscopy. Heart tissues were cut in $1-\mathrm{mm}^{3}$ blocks, fixed in half strength Karnovskys fixative ( $2 \%$ paraformaldehyde and $2.5 \%$ glutaraldehyde in phosphate buffer, $\mathrm{pH} 7.3$ ) for $2 \mathrm{~h}$, rinsed with the same buffer, and then postfixed in Caulfield's osmium tetroxide for $30 \mathrm{~min}$. Tissues were then rinsed with water, dehydrated in a graded ethanol series with $100 \%$ propylene oxide as a transitional solvent, and embedded in Epon 812 (Electron Microscopy Sciences, Fort Washington, PA). Thin sections were cut with an LKB ultramicrotome (Ultratone NOVA, LKB 2188, Bromma, Sweden) and transferred to copper grids. The grids were stained with lead citrate and uranyl acetate, and observed in a Hitachi H-300 electron microscope.

Total serum CK and LDH activity. The CK and LDH assay kits were purchased from Sigma Chemical Company (St. Louis, MO) (Cat No. 45-1 and Cat No. LD-340). Serum was collected within $2 \mathrm{~h}$ after obtaining blood by centrifugation at $6,000 \mathrm{~g}$ for $6 \mathrm{~min}$ in Microtainer Brand Serum Separator Tubes (Becton Dickinson, Rutherford, NJ).

Statistical analysis. Data were evaluated using the SAS system (SAS Institute Inc., Cary, NC). Analysis of variance (ANOVA) were performed for multiple comparison of each dependent variable. The CONTRAST command was used to test the statistical significance of each pre-planned comparison. $P$ value $<0.05$ was considered to be statistically significant. All data was presented as mean \pm SD.

\section{Results}

Characterization of transgenic mice. The expression of the steady state mRNA from the human MnSOD transgene in various organs of transgenic mice was initially demonstrated by Northern blot analysis (Fig. 2). Heart tissues had the most significant amount of human MnSOD mRNA expression compared with other organs. Lung tissues also had appreciable amount of expression. The expression in kidney tissues was limited. There was very little expression of mRNA in livers with visualization possible only after prolonged exposure of the x-ray films. These results indicated that the human MnSOD transgene was functional in the transgenic mice. An activity gel assay which facilitated the identification of SODs isoenzymes demonstrated the presence of human MnSOD activity in the heart 


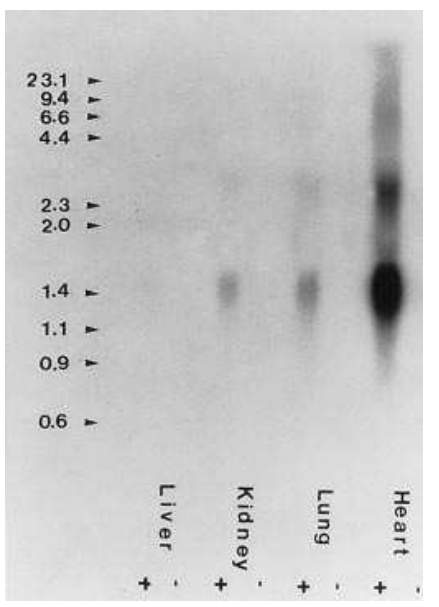

Figure 2. Detection of human MnSOD mRNA in different organs of mice. Northern analysis was performed for the total RNA isolated from hearts, lungs, kidneys, and livers. Ordinate is size of DNA molecular weight markers in kilo-

bases. - represents

nontransgenic mouse; + represents transgenic mouse. tissues of all three transgenic mice lines but not in their nontransgenic littermates (Fig. 3). Under the conditions of this activity gel, mouse MnSOD cannot be clearly visualized. The level of mouse CuZnSOD appeared unchanged in the transgenic mice when compared to nontransgenic mice (Fig. 3). Thus, the product of the human MnSOD transgene is functional and active in the heart tissues of transgenic mice. Three transgenic mice lines from three different founders exhibited a range of levels (low, Tg-SOD-L; medium, Tg-SOD-M; high, Tg-SOD-H) of human MnSOD activity (Fig. 3).

Since MnSOD is a mitochondrial enzyme, it is important to determine the intracellular location of the human MnSOD in the transgenic mice. To identify the intracellular site where human MnSOD was located, immunogold analysis at the electron microscopic level was performed. Immunogold staining of the heart tissues (Fig. 4) showed extensive labeling of the immunoreactive human MnSOD in the mitochondria of $\mathrm{Tg}$ SOD-H transgenic mice (Fig. $4 A$ ), but only light labeling in nontransgenic mice (Fig. $4 C$ ). MnSOD labeling was not observed in the cytoplasm or nucleus of either nontransgenic or transgenic myocytes. Controls using nonimmune serum showed no labeling (Fig. $4 B$ and $D$ ). Table I shows results of semiquantitation of immunogold bead for human MnSOD protein in mitochondria. There was an approximate fourfold increase in immunoreactive protein in the mitochondria of Tg-SOD-H mice compared to nontransgenic mice. These results demonstrated that the human MnSOD from the transgene was properly transported into the mitochondria in the heart tissues of transgenic mice.

To monitor the effect of increased MnSOD in the heart tissues of transgenic mice, we determined the activities of total MnSOD, CuZnSOD, CAT, and GPX in the heart tissues of the Tg-SOD-H transgenic mice line and their nontransgenic littermates (Table II). There was a significant increase in the total MnSOD in the heart tissues of the transgenic mice, but no significant changes in CuZnSOD, CAT, and GPX activities were found in transgenic mice. Activity assay indicated that there was an approximate twofold increase in total MnSOD activity. The discrepancy between MnSOD levels observed by immunogold and activity assay may reflect the fact that immunogold staining represents both active and inactive protein. On the other hand, the cDNA used in the transgene has an Ile-58 to Thr polymorphism. The Ile-58 was found to be involved in interaction of the four-helix bundle. Replacement of Ile-58

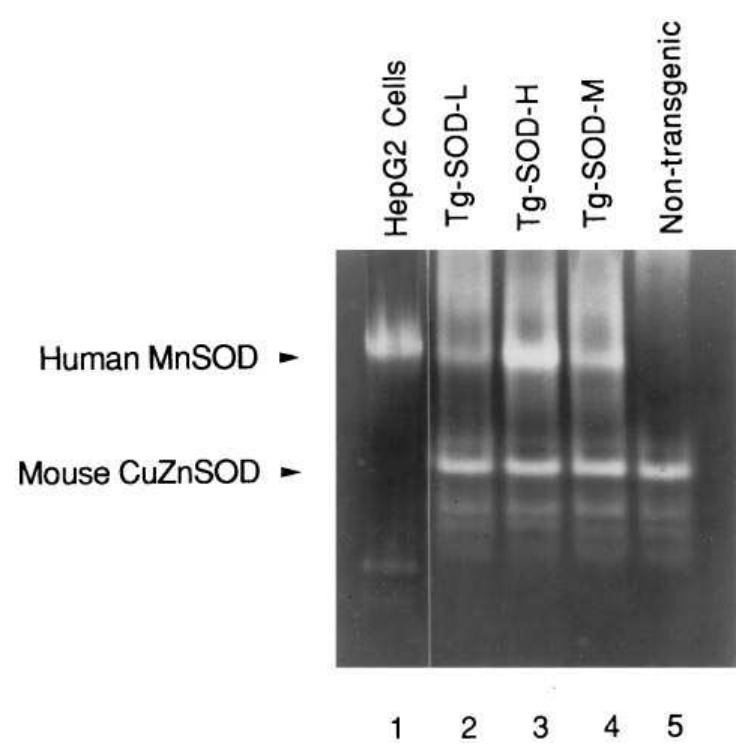

Figure 3. Native polyacrylamide gel stained for SOD activity in the heart and lung. Lane 1 represents human MnSOD activity in human hepatoma cells (HepG2 cells), which is used as a marker for human MnSOD isoenzyme; lanes 2, 3, and 4 represent human MnSOD activity in the heart of transgenic mice lines expressing low, high, and medium levels of human MnSOD respectively.

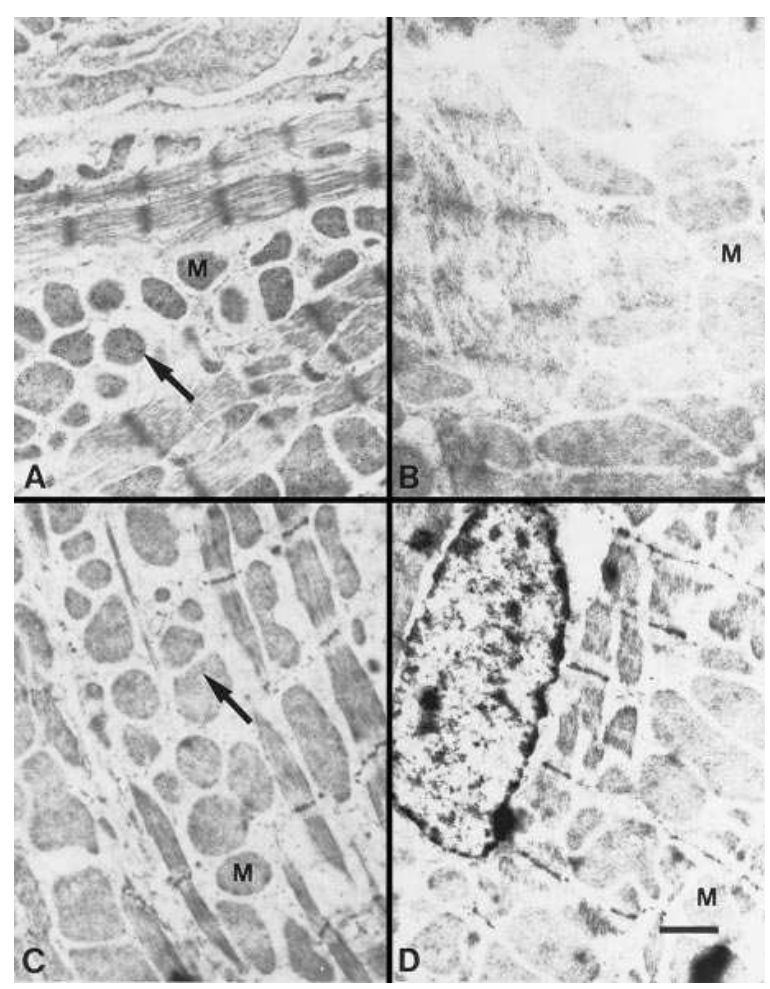

Figure 4. Immunogold labeling for human MnSOD protein in the heart of Tg-SOD-H transgenic mice. Rabbit polyclonal anti-human kidney MnSOD antisera were used to detect immunoreactive MnSOD. (A) Transgenic mice, labeled with anti-human MnSOD antiserum. $(B)$ Transgenic mice, labeled with nonimmune serum. (C) Nontransgenic mice, labeled with anti-human MnSOD antiserum. $(D)$ Nontransgenic mice, labeled with nonimmune serum. Labels: M, mitochondria. Arrows indicate immunogold staining in the mitochondria. 


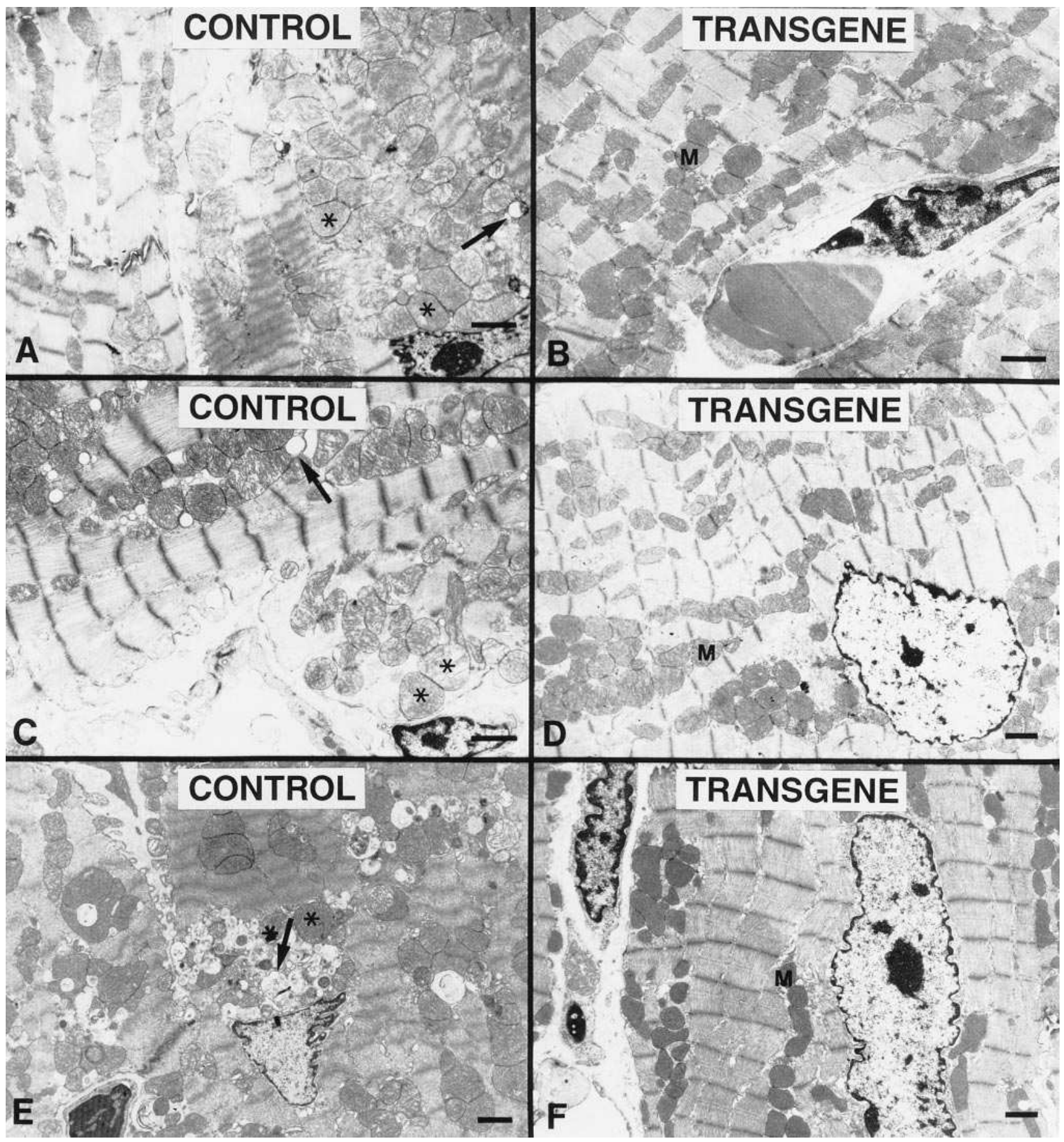

Figure 5. Electron micrograph of mouse heart after ADR treatment for $5 \mathrm{~d}$. (A) Nontransgenic mice treated with $10 \mathrm{mg} / \mathrm{kg}$ ADR. (B) Tg-SOD$\mathrm{H}$ transgenic mice treated with $10 \mathrm{mg} / \mathrm{kg}$ ADR. $(C)$ Nontransgenic mice treated with $20 \mathrm{mg} / \mathrm{kg}$ ADR. $(D)$ Tg-SOD-H transgenic mice treated with $20 \mathrm{mg} / \mathrm{kg}$ ADR. (E) Nontransgenic mice treated with $25 \mathrm{mg} / \mathrm{kg}$ ADR. $(F)$ Tg-SOD-H transgenic mice treated with $25 \mathrm{mg} / \mathrm{kg}$ ADR. Asterisks indicate damaged mitochondria. Arrows point to intracytoplasmic vacuoles, a nonspecific indicator of cell injury. Myofilament disarray is prominent in $A$ and $E$, but was also prominent in $C$, although not demonstrated in this micrograph.

with Thr may cause the helix bundle to be less stable leading to a lower enzymatic activity (33). Immunogold analysis of GPX in the hearts of transgenic and nontransgenic mice showed no differences in immunogold beads in myocytes (data not shown).

Ultrastructural pathology. To investigate the role of $\mathrm{Mn}-$ SOD in the protection against ADR-induced cardiac toxicity, Tg-SOD-H transgenic mice and nontransgenic mice were treated with ADR at doses of 10,20 , or $25 \mathrm{mg} / \mathrm{kg}$ for $5 \mathrm{~d}$. No definitive pathological changes were found in the heart tissues of nontransgenic and transgenic mice treated with ADR when examined by hematoxylin and eosin staining at the light microscopic level (not shown). However, when ultrastructural studies were performed, the ventricular tissues from ADR-treated nontransgenic mice showed marked myocardial damage at all 
Table I. Semiquantitative Immunogold Analysis of Human MnSOD Protein in the Mitochondria of Mouse Hearts

\begin{tabular}{lccc}
\hline & $\begin{array}{c}\text { Number of cells } \\
\text { counted }\end{array}$ & $\begin{array}{c}\text { Average } \\
\text { mitochondria/cell }\end{array}$ & $\begin{array}{c}\text { Average immunogold } \\
\text { bead/mitochondria }\end{array}$ \\
\hline NonTg/Ab & 5 & 50.0 & 2.1 \\
Tg-SOD-H/Ab & 5 & 53.6 & 9.9 \\
NonTg/NIS & 3 & 58.3 & 0.1 \\
Tg-SOD-H/NIS & 3 & 56.9 & 0.0
\end{tabular}

NonTg represents nontransgenic mice. Tg-SOD-H represents transgenic mice with high level of human MnSOD. Ab represents immunogold labeling with anti-human MnSOD antibodies. NIS represents labeling with nonimmune serum.

tested doses. These changes consisted of mitochondrial damage, the accumulation of intracytoplasmic vacuoles, and focal myofilament disarray (Fig. $5 A, C$, and $E$ ). Myocardial damage was dose dependent. The ventricles of transgenic mice treated with ADR showed normal ultrastructure of cardiomyocytes at all doses tested (Fig. $5 B, D$, and $F$ ).

Ultrastructural analysis of heart tissues from nontransgenic and transgenic mice treated with $25 \mathrm{mg} / \mathrm{kg}$ for $5 \mathrm{~d}$ indicated that the hearts of all transgenic mice were protected from ADR-induced subcellular damage. Nontransgenic mice treated with adriamycin showed extensive ultrastructural changes. These changes varied between individual myocytes (Fig. 6a, $c$, $e$ ) and consisted of mitochondrial damage, myofilament disarray, and cytoplasmic vacuolization. ADR-treated transgenic mice (Tg-SOD-L, Tg-SOD-M, and Tg-SOD-H) did not appear to show significant cardiac damage although occasional focal loss of cristae in the mitochondria was observed (Fig. 6b,d,f).

Semiquantitative analysis of the relative amount of abnormal mitochondria (Table III) indicated that the mitochondria of saline-treated Tg-SOD-H transgenic mice had a low frequency of mild alterations (minimal loss of cristae) in mitochondrial morphology compared to the saline-treated nontransgenic mice, while almost all mitochondria were markedly abnormal (extensive loss of cristae, intramitochondrial vacuoles, mitochondrial swelling, and abnormal shape) in the heart tissue of ADR-treated nontransgenic mice at the dose of 25 $\mathrm{mg} / \mathrm{kg}$. Most importantly, the mitochondria of ADR-treated Tg-SOD-H transgenic mice were distinctly protected from ADR-induced cardiac injury.

Serum $C K$ and $L D H$. Our pilot experiments showed that there were significant increases in serum CK and LDH in mice at $3 \mathrm{~d}$ after ADR treatment, but the levels declined at $5 \mathrm{~d}$ (data not shown). Total serum $\mathrm{CK}$ and $\mathrm{LDH}$ levels in mice treated with $25 \mathrm{mg} / \mathrm{kg}$ ADR for $3 \mathrm{~d}$ was shown in Tables IV and V. Two sets of experiments were performed. One set is for nontransgenic mice and Tg-SOD-L transgenic mice; the other set is for nontransgenic, Tg-SOD-M, and Tg-SOD-H transgenic mice. The serum $\mathrm{CK}$ and $\mathrm{LDH}$ in nontransgenic mice and transgenic mice after ADR treatment were both significantly different from that in their saline control groups $(P<0.002)$ for either $\mathrm{CK}$ or $\mathrm{LDH}$. There was no difference in $\mathrm{CK}$ or $\mathrm{LDH}$ levels between saline-treated nontransgenic mice and transgenic mice. The serum $\mathrm{CK}$ in Tg-SOD-H transgenic mice treated with ADR was significantly lower than that in nontransgenic mice treated with $\operatorname{ADR}(P=0.006)$. The serum
Table II. The Activities of MnSOD, CuZnSOD, GPX, and CAT in the Heart Tissues of Nontransgenic and Tg-SOD-H Transgenic Mice

\begin{tabular}{lcc}
\hline Enzyme activity & Nontransgenic & Transgenic \\
\hline units $/$ mg protein & $n=5$ & $n=5$ \\
MsSOD & $232 \pm 11.3$ & $484 \pm 81^{*}$ \\
CuZnSOD & $107 \pm 19$ & $128 \pm 36$ \\
GPX & $0.0394 \pm 0.0026$ & $0.0335 \pm 0.0057$ \\
CAT & $45.2 \pm 4.9$ & $39.7 \pm 4.6$
\end{tabular}

*Significant difference from the nontransgenic littermates $(P<0.05)$.

$\mathrm{LDH}$ in Tg-SOD-H transgenic mice was also significantly lower than that in nontransgenic mice treated with ADR $(P=$ 0.001). There was a slight decrease in CK and LDH for TgSOD-M transgenic mice compared with nontransgenic mice after ADR treatment, although it was not statistically significant $(0.1>P>0.05)$. There was no significant difference between nontransgenic mice and Tg-SOD-L mice after ADR treatment for both $\mathrm{CK}$ and $\mathrm{LDH}$.

\section{Discussion}

Our results are the first to demonstrate the protective role of MnSOD against ADR-induced cardiac toxicity in vivo and support the hypothesis that the generation of superoxide radicals in mitochondria plays an important role in ADR-induced cardiac toxicity. Increased MnSOD in transgenic mice may prevent cellular toxicity in the heart by scavenging superoxide radicals produced from ADR.

The ultrastructure of heart tissues in Tg-SOD-H mice demonstrated protection against ADR-induced cardiac injury in an ADR dose-dependent manner. Suppression of cardiac injury by elevated expression of human MnSOD in transgenic mice occurred in all three transgenic mice lines with different levels of MnSOD transgene. These results clearly indicated that increased level of MnSOD in the mitochondria play an essential role in the protection against ADR-induced cardiac toxicity. Although in the animals observed, there were no obvious relationship between MnSOD levels and the degree of myocardial protection, without morphometric quantitation, it would not be possible to determine whether such a relationship existed.

It has been shown that exogenous SOD was ineffective in protecting ADR-induced myocardial dysfunction of isolated rat papillary muscles (34). Transgenic mice overexpressing MnSOD endogenously, unlike exogenously administrated SOD, would be available to scavenge free radical generated from ADR endogenously in the mitochondria. Thus, our findings indicate that the presence of SOD at the appropriate cellular location is critical for the detoxification of ADR-induced tissue injury. It has been shown that some antioxidants or compounds with antioxidant properties could suppress ADRinduced myocardial injury in rodents $(2,4,35-37)$. However, these results did not clearly indicate the subcellular site where the antioxidants protected the cardiac tissue from ADR toxicity.

Our results suggest that free radical-mediated mitochondrial damage could be the primary and critical event in ADRinduced cardiac toxicity. Mitochondria have been identified as one of the targets in ADR-induced subcellular damage in the 


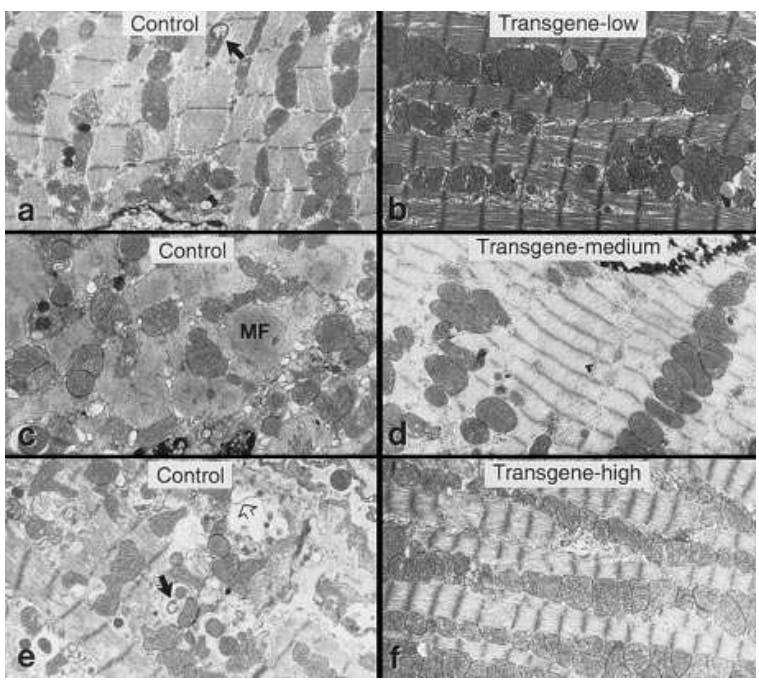

Figure 6. Electron micrograph of mouse heart after $25 \mathrm{mg} / \mathrm{kg}$ of ADR treatment for $5 \mathrm{~d}$ in nontransgenic mice and three lines of transgenic mice. $(a),(c)$, and $(e)$, nontransgenic mice treated with ADR. (b) Tg-SOD-L transgenic mice treated with ADR. (d) TgSOD-M transgenic mice treated with ADR. $(f)$ Tg-SOD-H transgenic mice treated with ADR. Mitochondria in $(a),(c)$, and $(e)$ show striking variation in size and shape, exhibit focal swelling and loss of cristae. Arrows in $(a)$ and $(c)$ indicate extensive loss of cristae. Myofilaments $(M F)$ show disarray with loss of Z-bands $(b)$. Double arrow in (c) shows that cytoplasmic vacuolization is apparent. Mitochondria in $(b),(d)$, and $(f)$ show uniform size and shape and have essentially normal internal morphology, although occasional loss of cristae may be observed. Cardiac myofilaments are also normal in treated transgenic mice.

heart (1), but its importance in relation to the alterations of other organelles have not been well documented. As shown in Figs. 5 and 6, the increase in the percentage of damaged mitochondria in the heart of nontransgenic mice corresponded with the degree of other subcellular changes. Most importantly, the protection of mitochondria by MnSOD against ADR-induced cardiac injury in transgenic mice also alleviated other ultrastructural alterations such as vacuolization and myofilament disarray observed in the heart of nontransgenic mice. Thus, our results suggest that mitochondrial damage mediated by free radicals is the critical and early event that subsequently resulted in other subcellular changes.

Since cardiac tissue is not an actively proliferating tissue, the significant cardiac toxicity caused by ADR is unlikely due to the interruption of DNA synthesis like the effect of ADR in tumors. The critical role of mitochondria shown in our study suggests that the sensitivity of myocardial tissue to ADR may be partially due to the high energy demand of the heart, and thus heart tissue is likely to be more dependent on the energy generation function of intact mitochondria than other organs. Resent studies of MnSOD knock out mice unequivocally demonstrated the importance of MnSOD in the normal heart, since those mice developed a severe cardiomyopathy (38).

It has been demonstrated that overexpression of $\mathrm{CuZn}$ SOD in cultured cells led to alteration of MnSOD and GPX activities (39-41). However, we did not observe any significant changes in CuZnSOD, CAT, and GPX activities in the transgenic mice expressing elevated levels of MnSOD (Table II). Thus, we demonstrated that increased expression of MnSOD
Table III. Semiquantitative Analysis of Mitochondrial Damage in the Heart Tissues of Nontransgenic Mice and Tg-SOD-H Transgenic Mice

\begin{tabular}{lcc}
\hline & Percent abnormal mitochondria & \\
\cline { 2 - 3 } Treatment & Nontransgenic & Transgenic \\
\hline Saline & $0.0 \%$ & $12.6 \% *$ \\
Adriamycin & $97.6 \% \S$ & $10.5 \% *$ \\
\hline
\end{tabular}

Heart tissues of nontransgenic mice or transgenic mice treated with 25 $\mathrm{mg} / \mathrm{kg}$ adriamycin for $5 \mathrm{~d}$ were examined by electron microscopy at $\times 5,600$. Five random cells from each experimental group were examined for mitochondrial morphology and the total number of normal and abnormal mitochondria were counted in each cell. Mitochondria were classified as abnormal if they exhibited loss of cristae, intramitochondrial vacuoles, mitochondrial swelling, or had abnormal size or shape. The results are expressed as percent abnormal mitochondria.

* Mitochondria were abnormal only in that some mitochondria showed mild focal loss of cristae.

ॠMitochondria showed many changes, including extensive loss of cristae, intramitochondrial vacuoles, mitochondrial swelling, and abnormal shape.

${ }^{\S}$ Average of 3 determinants.

in the heart did not cause elevation of other primary antioxidant enzymes as a result of adaptive responses. Our results were in agreement with those reported for transgenic mice overexpressing human MnSOD in the lung in which there were no significant changes in CuZnSOD, GPX, and CAT activities (42). It has been suggested that excessive amount of SOD may increase oxidative damage, and thus, the combination of SOD and CAT or GPX may be necessary to reduce oxidative stress rather than SOD alone (43-45). Our findings that $\mathrm{CuZnSOD}$, GPX, CAT activities were not changed significantly with increased MnSOD activity in the heart of MnSOD transgenic mice demonstrated that the protective effect seen in transgenic mice was due to the increased level of MnSOD activity.

The activities of serum CK and LDH have been widely used in the clinic as parameters for the diagnosis of cardiac dis-

Table IV. Total Serum CK Activities in Mice Treated with Saline or $25 \mathrm{mg} / \mathrm{kg}$ of $A D R$ for $3 \mathrm{~d}$

\begin{tabular}{llcccc}
\hline & & Saline & N & ADR & N \\
\hline Set I & NonTg & $200.9 \pm 128.2$ & 3 & $2206.5 \pm 858.3$ & 5 \\
& Tg-SOD-L & $133.8 \pm 54.4$ & 3 & $1706.0 \pm 608.6$ & 5 \\
Set II & NonTg & $141.7 \pm 19.4$ & 5 & $2342.3 \pm 425.7$ & 4 \\
& Tg-SOD-M & $99.6 \pm 45.8$ & 4 & $1931.2 \pm 410.7$ & 4 \\
& Tg-SOD-H & $84.9 \pm 42.5$ & 5 & $1563.4 \pm 593.4 *$ & 5
\end{tabular}

NonTg represents nontransgenic mice. Tg-SOD-L, Tg-SOD-M, and TgSOD-H represent transgenic mice expressing low, medium and high levels of human MnSOD. $\mathrm{N}$ is the sample size. The unit of the activity is International Units/liter. The $P$ values for the difference between saline and ADR-treated groups for either NonTg mice and three lines of transgenic mice are all smaller than 0.002 . There is no significant difference between saline-treated NonTg mice and all transgenic mice.

*Significant difference from ADR-treated nontransgenic mice $(P<$ $0.05)$. 
Table V. Total Serum LDH Activities in Mice Treated with Saline or $25 \mathrm{mg} / \mathrm{kg}$ of $A D R$ for $3 \mathrm{~d}$

\begin{tabular}{llllll}
\hline & & \multicolumn{1}{c}{ Saline } & N & \multicolumn{1}{c}{ ADR } & N \\
\hline \multirow{2}{*}{ Set I } & NonTg & $243.6 \pm 87.5$ & 3 & $2477.0 \pm 829.4$ & 5 \\
& Tg-SOD-L & $281.9 \pm 119.5$ & 3 & $2299.5 \pm 1196.8$ & 5 \\
Set II & NonTg & $307.1 \pm 167.9$ & 5 & $3033.6 \pm 571.3$ & 4 \\
& Tg-SOD-M & $146.6 \pm 30.5$ & 4 & $2533.2 \pm 482.3$ & 4 \\
& Tg-SOD-H & $2151.1 \pm 77.9$ & 5 & $1907.4 \pm 595.4^{*}$ & 5 \\
& & & & & \\
\hline
\end{tabular}

*Significant difference from ADR-treated nontransgenic mice $(P<$ 0.05). See legend for Table IV.

eases (46). As shown in Tables IV and V, the total serum CK and LDH were significantly increased in both nontransgenic mice and transgenic mice after treated with $25 \mathrm{mg} / \mathrm{kg}$ of ADR for $3 \mathrm{~d}$ compared with their saline controls. The increases in both CK and LDH in Tg-SOD-H transgenic mice were significantly lower than that in nontransgenic mice. However the reduction in both CK and LDH in Tg-SOD-M and Tg-SOD-L mice were not statistically significant. It has been well established that many conditions may cause the elevation of total serum CK and LDH, thus they are not absolutely specific for heart injury $(46,47)$. Since the elevated levels of MnSOD in other organs were not as great as in the heart, the increases in serum $\mathrm{CK}$ and LDH observed in ADR-treated transgenic mice may imply toxicities in other organs besides the heart. On the other hand, ADR may still cause a certain degree of tissue damage in the heart of transgenic mice, but the damage may not lead to subcellular ultrastructural alterations.

Since a major problem that limits the success of cancer therapy is dose limiting normal tissue toxicities, the results from this study should contribute significantly to the understanding of the defense of normal tissue against the toxic effect of oxygen radicals generated by therapeutic agents. We have previously shown that increased expression of MnSOD in a mouse fibrosarcoma cell line (FSa-II) suppressed the metastasis frequency of the cancer cells (48) and also reduced the tumor control radiation dose (49). Taken together, our results suggest that expression of MnSOD can enhance therapeutic efficiency by increasing the normal tissue defense capability and suppressing cancer invasion. Thus, it is possible that new concepts of cancer therapy such as the development of specific measures to augment MnSOD expression may lead to improvements in cancer treatment.

\section{Acknowledgments}

We thank Dr. L. Kedes of University of Southern California for his generous gift of the human $\beta$-actin expression vector $\mathrm{pH} \beta \mathrm{APr}-1$.

This work was supported in part by grants to D.K. St. Clair from National Institutes of Health (CA 49797 and CA 59835), KTRB (541113), and American Heart Association (Kentucky Affiliate), to YeShih Ho from NIH (HL 44571), and to T.D. Oberly from a VA Merit award.

\section{References}

1. Singal, P.K., C.M.R. Deally, and L.E. Weinberg. 1987. Subcellular effects of adriamycin in the heart: a concise review. J. Mol. Cell. Cardiol. 19:817-828.

2. Myers, C.E., W.P. McGuire, R.H. Liss, I. Ifrim, K. Grotzinger, and R.C. Young. 1977. Adriamycin: the role of lipid peroxidation in cardiac toxicity and tumor response. Science (Wash. DC). 197:165-167.
3. Powis, G. 1989. Free radical formation by antitumor quinones. Free Radical Biol. Med. 6:63-101.

4. Olson, R.D., and P.S. Mushlin. 1990. Doxorubicin cardiotoxicity: analysis of prevailing hypotheses. FASEB J. 4:3076-3086.

5. Halliwell, B., and J.M.C. Gutteridge. 1989. Free Radicals in Biology and Medicine. 2nd ed. Oxford University Press, New York. 543 pp.

6. Mimnaugh, E.G., M.A. Trush, M. Bhatnagar, and T.E. Gram. 1985. Enhancement of reactive oxygen-dependent mitochondrial membrane lipid peroxidation by the anticancer drug adriamycin. Biochem. Pharmacol. 34:847-856.

7. Doroshow, J.H. 1983. Effect of anthracycline antibiotics on oxygen radical formation in rat heart. Cancer Res. 43:460-472.

8. Ogura, R., M. Sugiyama, N. Haramaki, and T. Hidaka. 1991. Electron spin resonance studies on the mechanism of adriamycin-induced heart mitochondrial damages. Cancer Res. 51:3555-3558.

9. Fridovich, I. 1978. The biology of oxygen radicals. The superoxide radical is an agent of oxygen toxicity: superoxide dismutases provide an important defense. Science (Wash. DC). 201:875-880.

10. McCord, J.M., and I. Fridovich. 1969. Superoxide dismutase. An enzymatic function for erythrocuprein (hemocuprien). J. Biol. Chem. 244:60496055 .

11. Marklund, S.L. 1982. Human copper-containing superoxide dismutase of high molecular weight. Proc. Natl. Acad. Sci. USA. 79:7634-7638.

12. Weisiger, R.A., and I. Fridovich. 1973. Mitochondrial superoxide dismutase. Site of synthesis and intramitochondrial localization J. Biol. Chem. 248: 4793-4796.

13. Richter, C., V. Gogvadze, R. Laffranchi, R. Schlabach, M. Schweizer, M. Suter, P. Walter, and M. Yaffee. 1995. Oxidants in mitochondria: from physiology to diseases. Biochim. Biophys. Acta. 1271:67-74.

14. Kaul, N., N. Siveski-Iliskovic, M. Hill, J. Slezak, and P.K. Singal. 1993. Free radicals and the heart. J. Pharmacol. Toxicol. Methods. 30:55-67.

15. Hegstad, A.C., K. Ytrehus, R. Myklebust, and L. Jorgensen. 1994. Ultrastructural changes in the myocardial myocytic mitochondria: crucial step in the development of oxygen radical-induced damage in isolated rat hearts? $\mathrm{Ba}$ sic Res. Cardiol. 89:128-138.

16. Marcillat, O., Y. Zhang, and K.J.A. Davies. 1989. Oxidative and nonoxidative mechanisms in the inactivation of cardiac mitochondrial electron transport chain components by doxorubicin. Biochem. J. 259:181-189.

17. Matsumura, M., K. Nishioka, T. Fujii, M. Yoshibayashi, K. Nozaki, Y. Nakata, S. Temma, T. Ueda, and H. Mikawa. 1994. Age-related acute adriamycin cardiotoxicity in mice. J. Mol. Cell Cardiol. 26:899-905.

18. Neri, G.C., B. Neri, M. Bandinelli, M.D. Tacca, R. Danesi, and R. Riccardi. 1991. Anthracycline cardiotoxicity: in vivo and in vitro effects on biochemical parameters and heart ultrastructure of the rat. Oncology. 48:327-333.

19. Solem, L.E., T.R. Henry, and K.B. Wallace. 1994. Disruption of mitochondrial calcium homeostasis following chronic doxorubicin administration. Toxicol. Appl. Pharmacol. 129:214-222.

20. Ho, Y.-S., and J.D. Crapo. 1988. Isolation and characterization of complementary DNAs encoding human manganese-containing superoxide dismutase. FEBS Lett. 229:256-260.

21. Gunning, P., J. Leavitt, G. Muscat, S.-Y. Ng, and L. Kedes. 1987. A human $\beta$-actin expression vector system directs high-level accumulation of antisense transcripts. Proc. Natl. Acad. Sci. USA. 84:4831-4835.

22. Oury, T.D., Y.-S. Ho, C.A. Piantadosi, and J.D. Crapo. 1992. Extracellular superoxide dismutase, nitric oxide, and central nervous system $\mathrm{O}_{2}$ toxicity. Proc. Natl. Acad. Sci. USA. 89:9715-9719.

23. Hogan, B., R. Beddington, R. Costantini, and E. Lacy, E. 1994. Manipulating the Mouse Embryo. A Laboratory Manual. 2nd ed. Cold Spring Harbor Laboratory Press, Cold Spring Harbor, New York. 497 pp.

24. Laird, P.W., A. Zijderveld, K. Linders, M.A. Rudnicki, R. Jaenisch, and A. Berns. 1991. Simplified mammalian DNA isolation procedure. Nucleic Acids Res. 19:4293.

25. St. Clair, D.K., and J.C. Holland. 1991. Complementary DNA encoding human colon cancer manganese superoxide dismutase and the expression of its gene in human cells. Cancer Res. 51:939-943.

26. Chirgwin, J.M., A.E. Przybyla, R.J. MacDonald, and W.J. Rutter. 1979. Isolation of biologically active ribonucleic acid from sources enriched in ribonuclease. Biochemistry. 18:5294-5299.

27. Beauchamp, C., and I. Fridovich. 1971. Superoxide dismutase: improved assays and an assay applicable to acrylamide gels. Anal. Biochem. 44:276-287.

28. Spitz, D.R., and L.W. Oberley. 1989. An assay for superoxide dismutase activity in mammalian tissue homogenates. Anal. Biochem. 179:8-18.

29. Beers, R.F., and I.W. Sizer. 1952. A spectrophotometric method for measuring the breakdown of hydrogen peroxide by catalase. J. Biol. Chem. 195 133-140.

30. Paglia, D.E., and W.N. Valentine. 1967. Studies on the quantitative and qualitative characterization of erythrocyte glutathione peroxidase. J. Lab. Clin. Med. 70:158-169.

31. Lawrence, R.A., and R.F. Burk. 1976. Glutathione peroxidase activity in selenium-deficient rat liver. Biochem. Biophys. Res. Commun. 71:952-958.

32. St. Clair, D.K., X.S. Wan, T.D. Oberley, K.E. Muse, and W.H. St. Clair. 1992. Suppression of radiation-induced neoplastic transformation by overexpression of mitochondrial superoxide dismutase. Mol. Carcinogenesis 6:238242 
33. Borgstahl, G.E.O., H.E. Parge, M.J. Hickey, W.F. Beyer, R.A. Hallewell, and J.A. Tainer. 1992. The structure of human mitochondrial manganese superoxide dismutase reveals a novel tetrameric interface of two 4-helix bundles. Cell. 71:107-118.

34. Lee, V., A.K. Randhawa, and P.K. Singal. 1991. Adriamycin-induced myocardial dysfunction in vitro is mediated by free radicals. Am. J. Physiol. 261:H989-H995.

35. Al-Harbi, M.M., N.M. Al-Gharably, O.A. Al-Shabanah, A.M. Al-Bekairi, A.M.M. Osman, and H.N. Tawfik. 1992. Prevention of doxorubicin-induced myocardial and haematological toxicities in rats by the iron chelator desferrioxamine. Cancer Chemother. Pharmacol. 31:200-204.

36. Siveski-Iliskovic, N., M. Hill, D.A. Chow, and P.K. Singal. 1995. Probucol protects against adriamycin cardiomyopathy without interfering with its antitumor effect. Circulation. 91:10-15.

37. Kawasaki, S., S. Akiyama, T. Kurokawa, M. Kataoka, D. Kazuya, K. Kondoh, M. Yamauchi, K. Ito, T. Watanabe, S. Sugiyama, T. Ozawa, M. Matsuyama, and H. Takagi. 1992. Polyoxyethylene-modified superoxide dismutase reduces side effects of adriamycin and mitomycin C. Jpn. J. Cancer Res. 83:899_ 906.

38. Li, Y., T.-T. Huang, E.J. Carlson, S. Melov, P.C. Ursell, J.L. Olson, L.J. Noble, M.P. Yoshimura, C. Berger, P.H. Chan, D.C. Wallace, and C.J. Epstein. 1995. Dilated cardiomyopathy and neonatal lethality in mutant mice lacking manganese superoxide dismutase. Nat. Genet. 11:376-381.

39. Ceballos, I., J.M. Delabar, A. Nicole, R.E. Lynch, R.A. Hallewell, P. Kamoun, and P.M. Sinet. 1988. Expression of transfected human CuZn superoxide dismutase gene in mouse L cells and NS20Y neuroblastoma cells induces enhancement of glutathione peroxidase activity. Biochim. Biophys. Acta. 949: $58-64$

40. Kelner, M.J., and R. Bagnell. 1990. Alteration of endogenous glutathione peroxidase, manganese superoxide dismutase, and glutathione trans- ferase activity in cells transfected with a copper-zinc superoxide dismutase expression. J. Biol. Chem. 265:10872-10875.

41. Kelner, M.J., R. Bagnell, M. Montoya, L. Estes, S.F. Uglik, and P. Cerutti. 1995. Transfection with human copper-zinc superoxide dismutase induces bidirectional alterations in other antioxidant enzymes, proteins, growth factor response, and paraquat resistance. Free Radical Biol. Med. 18:497-506.

42. Wispe, J.R., B.B. Warner, J.C. Clark, C.R. Dey, J. Neuman, S.W. Glasser, J.D. Crapo, L.-Y. Chang, and J.A. Whitsett. 1992. Human Mn-superoxide dismutase in pulmonary epithelial cells of transgenic mice confers protection from oxygen injury. J. Biol. Chem. 267:23937-23941.

43. Amstad, P., A. Peskin, G. Shah, M.-E. Mirault, R. Moret, I. Zbinden, and P. Cerutti. 1991. The balance between $\mathrm{Cu}, \mathrm{Zn}$-superoxide dismutase and catalase affects the sensitivity of mouse epidermal cells to oxidative stress. Biochemistry. 30:9305-9313.

44. Mao, G.D., P.D. Thomas, G.D. Lopaschuk, and M.J. Poznansky. 1993. Superoxide dismutase (SOD) catalase conjugates. Role of hydrogen peroxide and the Fenton reaction in SOD toxicity. J. Biol. Chem. 268:416-420.

45. McCord, J.M. 1993. Human disease, free radicals, and the oxidant/antioxidant balance. Clin. Biochem. 26:351-357.

46. Zimmerman, H.J., and J.B. Henry. 1988. Clinical enzymology. In Clinical Diagnosis and Management by Laboratory Methods. J.B. Henry, editor. The W.B. Saunders Company, Philadelphia, PA. 251-258.

47. Lang, H. 1981. Creatine Kinase Isoenzymes. Springer-Verlag Berlin Heidelberg, New York. 317 pp.

48. Safford, S.E., T.D. Oberley, M. Urano, and D.K. St. Clair. 1994. Suppression of fibrosarcoma metastasis by elevated expression of manganese superoxide dismutase. Cancer Res. 54:4261-4265.

49. Urano, M., M. Kuroda, R. Reynolds, T.D. Oberley, and D.K. St. Clair. 1995. Expression of manganese superoxide dismutase reduces tumor control radiation dose: gene-radiotherapy. Cancer Res. 55:2490-2493. 